\title{
Tourism Curriculum in a Global Perspective: Past, Present, and Future
}

\author{
Walanchalee Wattanacharoensil ${ }^{1,2}$ \\ ${ }^{1}$ Tourism and Hospitality Management Division, Mahidol University International College, Thailand \\ ${ }^{2}$ School of Hotel and Tourism Management, the Hong Kong Polytechnic University, Hong Kong \\ Correspondence: Walanchalee Wattanacharoensil, Tourism and Hospitality Management Division, Mahidol \\ University International College, 73170 Nakhon Pathom, Thailand. Tel: 66-876-847-542. E-mail: \\ walanchale.wat@mahidol.ac.th
}

Received: October 8, 2013 Accepted: November 18, 2013 Online Published: December 12, 2013

doi:10.5539/ies.v7n1p9 URL: http://dx.doi.org/10.5539/ies.v7n1p9

\begin{abstract}
This article summarizes the development of tourism curricula over the past 20 years from the perspective of global tourism. The paper proposes a generic framework for a future tourism curriculum on the basis of a review of literature in the American, British, and other European contexts. The proposed tourism curriculum aims to create well-rounded tourism graduates who view the tourism industry as a fully integrated system, are aware of the importance of connectivity in society, and can make appropriate contributions based on current demands and situations. Once understood and delivered by tourism graduates, the implicit value embedded in the tourism curriculum will inspire respect for this curriculum in higher education. In addition, balance in the development of the tourism industry is expected to be achieved in the future.
\end{abstract}

Keywords: tourism, curriculum, development, framework

\section{Introduction}

The tourism curriculum has been undergoing the development process for over two decades. Tourism education had its beginnings in technical or vocational schools (Airey, 2004; Lo, 2005; Inui, Wheeler, \& Lankford, 2006). Recent years have witnessed the rise and development of tourism education in both undergraduate and graduate levels. This development results from the rapid growth and demand of the tourism sector. Hence, academic institutions and universities established or expanded their tourism programs. Tourism education continued to develop based on the original emphasis on technical/vocational and knowledge and skills development. Along with the higher demand from the tourism business sector, many undergraduate level tourism curriculums were placed under the scope of hotel and hospitality management. In addition, business knowledge and skills were embedded within the curriculum.

Despite the spread of tourism education, especially in the undergraduate level, debates has focused on the curriculum and the direction where it should lead. As Inui et al. (2006, p. 26) point out:

"Debates over tourism programs at universities appear to center on the balance between vocational and academic focus. Tourism courses in higher education are often referred to as vocational (Busby, 2001) with educators mainly focusing on producing skilled and knowledgeable personnel for the industry. This emphasis has given short shrift to the value or meaning of tourism education."

A paradox arises within the dominant representation. Tourism perpetuates based on the underpinnings of the business management framework (Tribe, 2005; Ayikoru, Tribe, \& Airey, 2009). However, in truth, other related knowledge fields, mainly in sociology, can be used in the study and understanding of the tourism phenomenon. Consequently, tourism academics are urged to rethink and to research the approaches behind the overall development of the tourism curriculum (Tribe, 1997; Airey \& Johnson, 1999; Tribe, 2005; Inui et al., 2006). Studies concerning the direction to which the tourism curriculum should be adapted and improved could also be of interest (Smith \& Cooper, 2000; Dale \& Robinson, 2001; McKercher, 2002; Tribe, 2005).

This paper attempts to examine tourism curriculum development on the undergraduate level by taking the key perspectives from tourism schools or departments mainly in Europe, UK, and US, and proposes a generic framework for a future tourism curriculum. Our research covers the period before 1990 until the present, which shows the evolution of the tourism curriculum. In addition, our study determines the status of tourism curriculum 
development. The review of literature helps in obtaining more insight on the evolution and development of the tourism curriculum. Literature also helps determine the existing curriculum design areas that require improvement. The paper accomplishes the analysis of the literature as follows. The literature review is divided into two parts. Part I, "Overview of tourism curriculum development," discusses the path of tourism curriculum development according to three main periods, which cover the time before 1990 up to the present. Part II, "Constructing tourism curriculum: Approaches and models," presents the important components of tourism curriculum design. In addition, the main obstructions and arguments that hinder the tourism curriculum from becoming an objective form of study are also elaborated. Lastly, the proposed curriculum development theoretical framework is formulated based on the gaps derived from the extensive literature. The author believes that the proposed framework creates what Ayikoru et al. (2009) call "the respectability" of tourism curriculum in higher education.

\section{Literature Review}

\subsection{Part I: Overview of Tourism Curriculum Development}

In this section, tourism curriculum development is elaborated beginning at a period before 1990, between 1990 and 2000, and from 2000 to the present. The development timeline of tourism studies represents the dynamic thoughts of the educational tourism community during these periods.

\subsubsection{Before 1990: What Tourism Knowledge Is Taught in Tourism Education?}

Courses in tourism were initially introduced in technical and vocational schools. Courses were then transitioned into undergraduate and graduate programs (Ring, Dickinger, \& Wober, 2009). Numerous tourism education frameworks exist around the world. Tourism education was established in the UK sometime around the mid 1960s (Lashley, 2004). The period of establishment was similar to North America (Jafari, 1977), and Europe (Bodewes, 1981; Airey \& Middleton, 1984). In comparison with European pedagogy, North American academics were observed to deal with tourism education with a more pragmatic approach (Bodewes, 1981). Nevertheless, Ayikoru (2004) otherwise witnessed that both North America and the UK tended to allow the vocational sector to lead the direction of education. In the mid 1970s, many schools in Europe still viewed tourism as closely connected to recreation. This conception resulted in integrating tourism and recreational studies. Leisure studies sufficed some time after. Business travel was only seen as a peripheral area of tourism (Bodewes, 1981). The Annals of Tourism Research in 1981 with the theme of "tourism education" (Jafari \& Ritchie, 1981 cited in Ayikoru et al., 2009) paved the way for tourism studies to receive great academic attention during the late 1970s.

Since the initial development of the tourism program, the direction for the creation of the tourism curriculum was unclear. Jafari and Ritchie (1981, p. 14) stated, "Unless the contextual boundaries and concerns of tourism are known, it is difficult to even suggest what tourism education involves and what should be studied." The definition of tourism proposed by Jafari $(1977$, p. 8) is:

“... a study of man away from his usual habitat, of the industry which responds to his needs, and of the impacts that both he and the industry have on the host socio-cultural, economic, and physical environments".

This definition raised several questions about the knowledge tourism courses should offer. Such questions include "What makes travelers different from consumers of other goods and services? What motivates people to be away from home? What can guarantee satisfactory consumption of the tourism product?" Further issues concerning how tourism fits into the business travel industry could be raised and understood because vagueness persists in the travel industry and other disciplines (Jafari \& Ritchie, 1984). Bodewes (1981) believes tourism is an application of established disciplines, as tourism does not have sufficient doctrinal processes to be classified as a full academic discipline.

Given these reasons, there propose a multi-, inter-, or trans-disciplinary approach to tourism studies (Bodewes, 1981; Jafari \& Ritchie, 1984). Jafari and Ritchie (1981) define these three approaches as accordingly. Multi-disciplinary studies involve several disciplines that focus on one problem. Inter-disciplinary studies involve the integration of concepts and ideas that are essential to the teaching approach. Trans-disciplinary studies involve bringing the knowledge of different disciplines to contribute resolutions to a given problem or issue. Trans-disciplinary study is the highest level of integrated study. Specifically, this approach implies studying beyond the disciplines. However, both inter- and trans-disciplinary approaches are very difficult to achieve in tourism education. These approaches require highly qualified academics and highly talented students to achieve and accomplish these purposes.

Moreover, a study of the British tourism education system reveals that, while some attention may be given to 
tourism, "it is the sector or the discipline and not tourism itself which is the main focus of attention" (Airey, 1979, p. 13). Subjects, such as tourism marketing or tourism economics, focus on marketing or economic aspects rather than on tourism. In addition, the effort to teach tourism using the multi-disciplinary approach "broadens" the study as it allows "a bit of everything," but gives it "no depth." Hence, tourism knowledge grew to be regarded as a lower level of knowledge when compared with economics or science. In contrast with tourism, specific fields of studies require explicit knowledge (Bodewes, 1981). Jafari and Ritchie (1981) state that, until tourism can transition into inter- or trans-disciplinary approaches (Jafari \& Ritchie, 1981), a challenge manifests on the road of tourism education. The nature of tourism is subjected to several disciplines (Bodewes, 1981; Jafari \& Ritchie, 1981), which make it difficult for tourism to instill core strength in the subject. Around the end of the period, more focus and specialized programs in hotel administration arose to cope with the immediate demands of the travel industry. This condition developed because of the existing complexity of the tourism concept and the recent boom of tourism business sectors. The phenomenon would be clearly reflected in the next period.

\subsubsection{The 1990s to 2000: When Business Became the Focus}

The period between the 1990s and 2000 was dedicated to the attempts of educators to set and to clarify the scope of tourism education, especially in the United States and United Kingdom. However, several studies during this period found that most curricula did not include the full scope of tourism. Rather, curricula diverted their focus to the hospitality industry. If this focus was not the case, curricula moved towards business emphasis (Koh, 1995; Gunn, 1998). The study of Koh (1995) covers 150 tourism educators and 18 national organizations in the United States. The study reveals the common elements desired in an undergraduate tourism management degree. More specifically, this degree involved elements, such as the lodging and food service sectors. Students were required to develop skills in 1) human management, 2) marketing, 3) entrepreneurship, 4) written communication, 5) interpersonal relations, 6) microcomputer literacy, and 7) hotel-restaurant operation and services (cited in Gunn, 1998). In line with tourism curriculum goals in tourism business context, technical skills evidently complied with expected knowledge outcomes. Although the study was conducted in the US, the phenomenon occurred in parallel with the UK as indicated in the similar results of Airey and Johnson (1999).

In the early 1990s, the Council for National Academic Awards (1993, p. 37) in the UK highlighted the general unease felt with regard to the tourism program. The feelings of unease were derived from the lack of "basic definition of tourism as a subject for study or the parameters within which it should develop" (cited in Airey \& Johnson, 1999). Tourism educators thus took on the tourism industry as a parameter for curriculum development. As such, later stages of curriculum development focused on developing skills and outputs required by the industry rather than on integrating philosophical aspects into the curriculum. A similar phenomenon occurred in the US. Koh (1995) mentioned that rather than leaving the task of curriculum development to educators, involvement of the tourism industry in curriculum development process was needed. Middleton and Ladkin (1996) further determined that, if tourism is only allowed to mean what academics want it to mean, then two gaps might arise. First, confusion may develop on the part of applicants and their conceptions of the courses, students, and potential employers. Second, only limited opportunities exist for tourism to continue its development into a robust and coherent area of study.

The tourism curriculum issue at the end of this period remained based on subject content (core body of knowledge), rather than considering curriculum as a whole body that embraces processes and outcomes (Airey \& Johnson, 1999). The fact that the core body of knowledge of tourism was in favor of business elements created the unease for non-business elements. This issue is further addressed in the subsequent period of the 2000s. Gunn (1998) stated that the multi-disciplinary approach of tourism was greatly affected when universities subsumed the tourism curriculum under their organizational structure in accordance with the nature of both faculty and school (i.e., faculty of business or social science). Gunn (1998) considered the career-oriented aspect of curriculum building, and thus, suggested that university, college, and school administrators should anticipate the needs of tourism personnel before developing the curriculum.

At the end of this period, a demand for tourism education "standardization" appeared, especially in the UK tourism environment. In 1999, Tribe proposed a tourism definition that provides more clarity of content:

"The sum of the phenomena and relationships arising from the interaction in generating and host regions, of tourists, business suppliers, economies, governments, communities, and environments."

This definition allows tourism to be seen and split into two different scopes, namely, business and non-business aspects. This definition also triggered ideas regarding non-business approaches that should be designed as core knowledge in the tourism curriculum for the twenty-first century. 


\subsubsection{During the 2000s up to the Present: Are We Influenced by Neoliberal Phenomenon or Not?}

Tourism education literature during this period initially determined the direction of the tourism curriculum by employing various methodological paradigms. Tribe (2001) mentions three methodological paradigms of curriculum design, namely, the scientific positivist, the interpretive, and the critical approaches. He stressed the vital points of these methodologies, and that "...the proper attention to methodology of curriculum design instead of a rush to a preferred method will mean that the problem of the meaning of tourism education is addressed (Tribe, 2001, p. 443). This problem could result in tourism elements with social, philosophical, or psychological" facets that would not be overwhelmed by dominant business aspects. The scientific positivist paradigm entails that the contents of the curriculum be derived from verifiable positive data and tested using hypothesis formulation. Although the outcome of the tourism curriculum would fill in the essential subject components, the critical view of society would be missed if the scientific-positivist paradigm were used (Tribe, 2002). However, this gap, where interpretative and critical approaches both allow opinions to be voiced, includes areas excluded from the scientific positivist perspective. Inui et al. (2006) further support this point by stating that the sociology and philosophy of tourism should be included in the curriculum because these areas would provide students with the basis to address epistemological issues. Additionally, the supplementation of sociology and philosophy would allow students to think critically about tourism (Inui et al., 2006).

The study of Ayikoru et al. (2009) on tourism in UK higher education uses post-structuralist discourse theory to examine the ideological influences in tourism curriculum. The study reveals that neo-liberalism manifests in the tourism curriculum being created. As such, the definition of tourism was conveyed in the business sense where key players include the industry and employers. Botterial and Gale (2005) observe that tourism in higher education was increasingly politicized as a part of macro-economic policy and international relations. This politicization reflects how tourism is a driver of the post-modern economy and how tourism greatly influences the business facet. This view was further reinforced by government funding that tends to support and to encourage higher education institutions to work in partnership with industry and commerce. In this way, economic competitiveness was ensured. Higher education institutions in Asian countries, such as China (Zhang \& Fan, 2005) and Thailand (Chaisawat, 2006), embrace the neo-liberal approach to tourism education. Several calls for cooperation with the industry were evident through tailor-made and training programs. As mentioned by Ayikoru et al. (2009, p. 209):

“...the overall goal here is to ensure higher education plays an important part in creating and enhancing the competitiveness of the economy...implying an overt attempt at policy level to espouse neo-liberalism as a dominant ideology in higher education."

Another important aspect in this period goes back to early 2000, when Tribe proposed "curriculum space" as a tool that enables educators to visualize important steps in curriculum design. Tribe's idea was based on the problem of the pre-paradigmatic state of tourism where "there exists a variety of different knowledge systems in operations" (Kuhn, 1970 cited in Tribe, 2005). Tribe also mentions that the remaining problems in defining tourism knowledge indicate knowledge choices have to be made with regard to the curriculum. Tribe's "curriculum space" would be populated with an array of possible knowledge, skills, and attitudes. Hence, the curriculum space would help in framing tourism knowledge based on the influence, power, and interest of parties alongside the particular knowledge framed within the curriculum (Tribe, 2002; Lewis, 2004). Figure 1 shows the curriculum space proposed by Tribe. Here, the $\mathrm{X}$ and $\mathrm{Y}$ circles represent the particular framing of the curriculum. The actual content of the framed curriculum would depend on the power exerted by these interests. For example, $\mathrm{X}$ illustrates the outcome subjects when the government exerts strong control. Y illustrates a curriculum influenced by lectures in critical subjects (Tribe, 2005).

Further study by Ring et al. (2009) suggests some elements are still lacking in the tourism curriculum. These elements pertain to the focus on future tourism, sustainability, information technology, and the creation of "philosophic practitioners" as Tribe had proposed in 2002. The next section further discusses the idea of philosophic practitioners. 


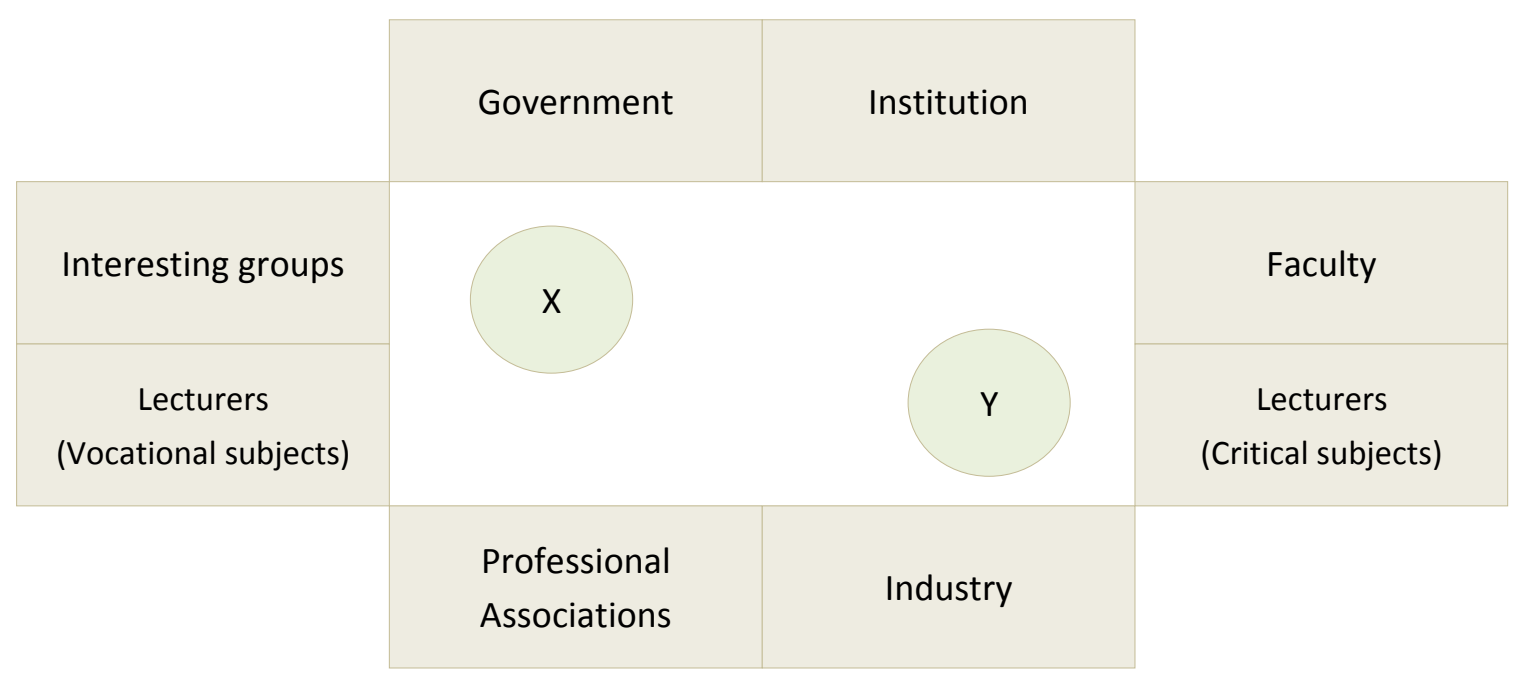

Figure 1. Curriculum space according to Tribe (2005)

In conclusion, the main stream persisted in attempts to attain the market relevance of the tourism curriculum in this period. Such a condition was not distant from the direction Koh determined tourism curriculum would take in 1995. However, more mechanisms must be proposed to enhance the systematic and critical thinking process upon curriculum design implementation.

\subsection{Part II: Constructing the Tourism Curriculum: Approaches and Models}

Smith and Cooper (1999) believe curriculum must be context-related rather than context-bound. This statement urges academics to rethink appropriate curriculum designs containing the necessary content, while also providing room for knowledge flexibility (Rowntree, 1982; Scrimshaw, 1983; Lawton, 1989; Squires, 1990; Goodlad, 1995; Tribe, 2002). Coming from a broad perspective, Lawton (1989) suggests that the curriculum planning model should start with two initial stages, namely, philosophical and sociological analyses. Philosophical questions relate to the aims of education and the meaning of worthwhile education. By contrast, sociological questions relate to the present society. A tourism curriculum requires the development of a tourism society, that is not just for businesses but, rather, for all stakeholders (Tribe, 2001).

Taylor and Richards (1985) define curriculum as that which is taught. Tribe (2002) provides a more complex definition, in which curriculum is “...defined as a whole educational experience packaged as a degree program (p. 340)." Gunn (1998, p. 74) states that the curriculum is "a series of courses of instruction that lead to graduation or certification or a degree, diploma, or similar terminal award".

Translating the broad definition of "curriculum" into something more tangible and being able to deliver curriculum aims is not easy. The early and rigid view of curriculum design was derived from the UK National Liaison Group for Higher Education in Tourism (NLG) (Holloway, 1995, p. 2 cited in Tribe, 2005). NLG aimed to seek a consensus on the body of knowledge that would be acceptable to both academics and practitioners in the tourism industry.

The seven core subject areas of NLG are:

(1) Meaning and nature of tourism.

(2) Structure of the industry.

(3) Dimensions of tourism and issue of measurement.

(4) Significance and impacts of tourism.

(5) Marketing of tourism.

(6) Tourism planning and development.

(7) Policy and management in tourism. 


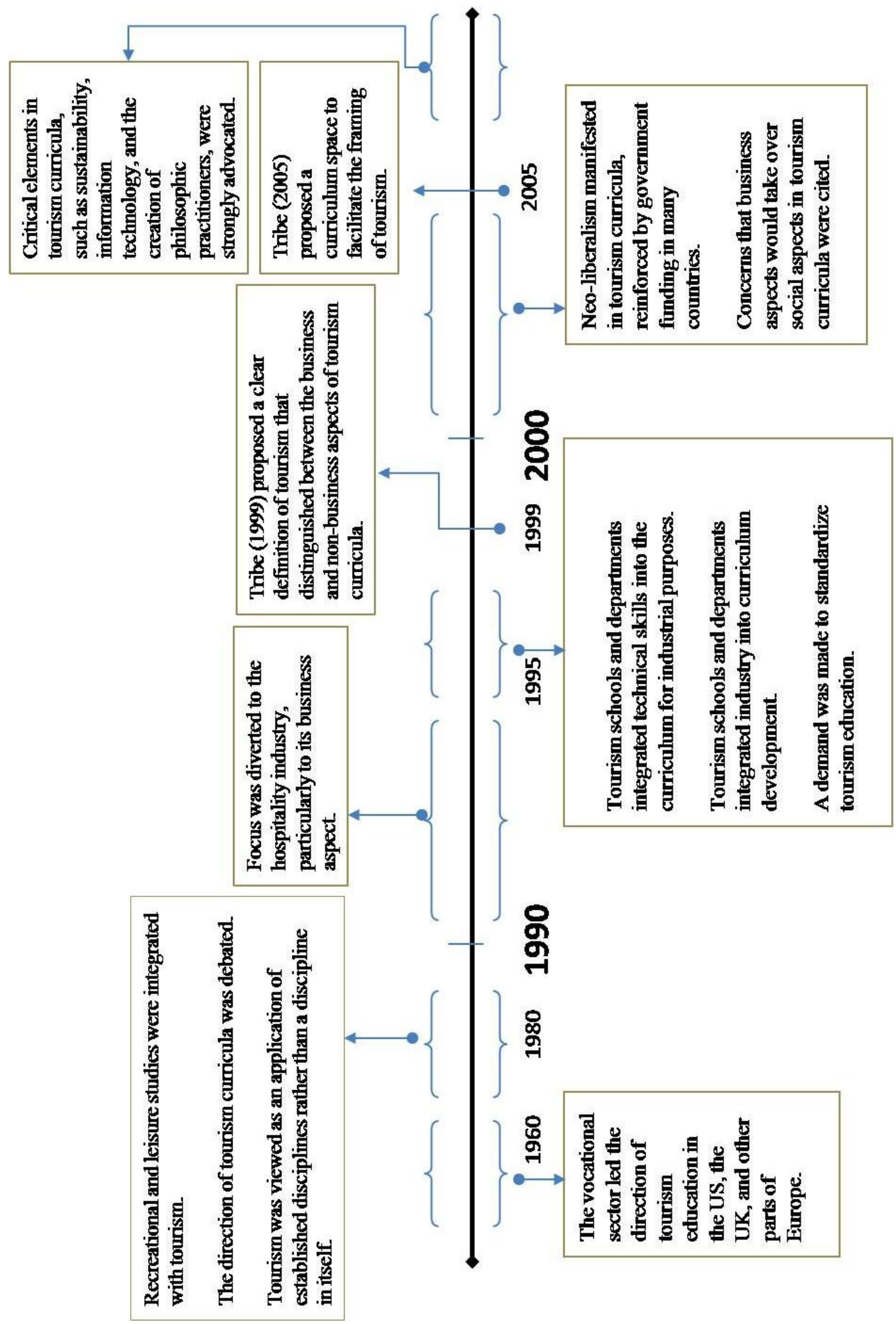

Figure 2. Key events of tourism curriculum development in each period 
Tribe (2005, p. 54) comments that the above core subject areas articulate the key aspects of the vocational tourism curriculum. However, these subjects "avoided philosophical issues of alternative ends of tourism education...lack of articulation of ethical elements of tourism or the accommodation of disciplinary, critical or non-business approaches to the field" because the NLG results were conducted based on a scientific positivist paradigm. Tribe also further refers to the proposed curriculum by Koh (1995), whose curriculum design and input was sought to fulfill the needs of the industry. Tribe (2005, p. 54) comments that the "...Koh curriculum included ethics and social responsibility but, like the NLG core it is still essentially dominated by vocationalist thinking-a curriculum for the industry with a quite narrow view of tourism." In 2000, the NLG held another series of consultative meetings to align the core tourism subject areas with the tourism subject community. In turn, the following subject areas were agreed upon:

(1) Concept and characteristics of tourism as an area of academic and applied study.

(2) Nature and characteristics of tourists.

(3) Structure of and interactions in tourism industry.

(4) Role of tourism in communities and environments that it affects.

(5) Nature and characteristics of tourists.

This core knowledge of subjects provides the main strengths in terms of avoiding the narrow confines of the tourism curriculum. Such narrowness may excessively focus on the vocational aspect and give weight to disciplinary knowledge, communities, environments, and ethical issues. However, the main weakness was still perceived. There was dynamism to the different aspects and a freedom to curriculum construction within the curriculum space because of too much theory. Along with the ability to interpret core subjects, achieving full richness in the curriculum space became constrained. Tribe (2005) stresses the process of curriculum evaluation to design effectively the curriculum. Questions should be answered regarding if the curriculum delivers its stated aims, whether it is coherent, offers breadth, balanced, integrates theory and practice, and gives progression (Tribe, 2005).

Another aspect of curriculum design pertains to the notion of "implicit values" that accompany the curriculum (Silver \& Brennan, 1988; Lawton, 1989; Squires, 1990; Tribe, 2005). Academics have long addressed several implicit values of the curriculum. Ideas have been taken for granted numerous times because values are implicit. As such, these ideas were not used for the critical purpose of designing or developing curriculum. For example, Silver and Brennan (1988) analyze the vocational curriculum as a continuum along a vocational-liberal axis. They define vocational curriculum as a curriculum for employment. By contrast, the liberal curriculum is a curriculum involving thinking and reflection. Tribe (2002) further develops the idea of Silver and Brennan for tourism in higher education and adds two key domains, namely, action and reflection, into both groups. Hence, the final framework (Tribe, 2002) consists of four key domains, which are vocational action, vocational reflection, liberal reflection, and liberal action. This design would educate "philosophic practitioners" who:

"...deliver efficient and effective tourism services, attempt a comprehensive understanding of the tourism phenomenon while at the same discharging, the role of stewardship for the development of the wider tourism world in which these services are delivered."

Other ideas concerning the implicit values of the curriculum were proposed by Lawton $(1989,1996)$. He added a cultural analysis model in the curriculum. Lawton (1989) subdivided culture into nine systems and believed that the compulsory curriculum should ensure that these nine aspects of culture are transmitted. Furthermore, Squires (1990, p. 53) offers a framework with three dimensions, namely, 1) curriculum as knowledge, 2) curriculum and culture, and 3) curriculum and student development. Squires uses the terms "object", "mode", and "stance" to describe their implications in the curriculum. Object defines what the course is about. Mode defines the philosophical problem that examines the degree of critical engagement students make with the disciplines. Stance distinguishes broadly between the intention of knowing and the intention of doing. Goodlad (1995, p. 21) proposes a curriculum space, which conceptualizes four dimensions of theory, practice, society, and the individual. These dimensions were described as "the institutional correlatives of the social, personal, intellectual, and practical dimensions of the person." As such, these dimensions dominate student development. Table 1 summarizes the implicit value components of curriculum development based on these thinkers. 
Table 1. Curriculum frameworks adapted from Tribe (2005)

\begin{tabular}{|c|c|}
\hline Framework & Components \\
\hline \multirow{2}{*}{ Silver and Brennan (1988) } & Liberal \\
\hline & Vocational \\
\hline \multirow{9}{*}{ Lawton (1989) } & Socio-political system \\
\hline & Economic system \\
\hline & Communications system \\
\hline & Rationality system \\
\hline & Technology system \\
\hline & Morality system \\
\hline & Belief system \\
\hline & Aesthetic system \\
\hline & Maturation system \\
\hline \multirow{3}{*}{ Squires (1990) } & Knowledge \\
\hline & Culture \\
\hline & Student development \\
\hline \multirow{4}{*}{ Goodlad (1995) } & Theory \\
\hline & Practice \\
\hline & Society \\
\hline & Individual \\
\hline \multirow{4}{*}{ Tribe (2002) } & Vocational \\
\hline & Liberal \\
\hline & Reflection \\
\hline & Action \\
\hline
\end{tabular}

In general, tourism schools develop curriculums based on different aims and outcomes. For example, the study by Ring et al. (2009) demonstrates the diversity of 64 tourism bachelor programs taught in English. The study reveals that various dominant foci on tourism programs are on management, social tourism, tourism marketing, environment, nature, and eco-tourism.

Tourism education has yet to overcome its traditional focus and, thus, still offers numerous vocational skills (Busby, 2001; Tribe, 2002; Airey, 2005; Ring et al., 2009). However, Ring et al. (2009) point out that one of the obstacles of vocational education lies in equipping students with skills in the tourism environment without questioning the existence and occurrence of such an environment. Ring et al. (2009) calls this condition as the "narrow tourism society," which pertains to a society that is largely unaware of the broader world and meaning of tourism. Hence, the ability to change the world of tourism, if necessary, is not obtained (Ring et al., 2009). Although tourism study from the vocational or skilled perspective has been upgraded and entwined with the liberal knowledge of social science (Tribe, 2005), critiques and concerns regarding the undergraduate level tourism curriculum still exist. Such criticisms focus more on the skills or technical expertise required by the industry, and contributes to an injudicious and unquestioned reproduction of an imperfect society (Tribe, 2001, 2002; Inui et al., 2006; Ring et al., 2009). For over a decade, the belief that "higher education should and can do more than simply provide graduates with a toolkit to manage the (short-lived) present" has been discussed and presented in the tourism curriculum (Ring et al., 2009). In doing so, the "philosophic practitioner" is to be produced and equipped with necessary skills for tourism industry. At the same time, the "philosophical practitioner" must have strong social and philosophical knowledge to understand and to react appropriately to the nature of tourism. Others who hold the view that tourism education is a means to produce graduates capable of making future innovations, rather than graduates who are "servants" of the current environment, agree with this perspective (Morrison \& O’Mahony, 2003; Morgan, 2004 cited in Ring et al., 2009). 


\section{Proposed Conceptual Framework for Tourism Curriculum as Part of a Larger System}

The considerable debate regarding the tourism curriculum demonstrates the inadequacy of tourism knowledge in relation to society, the main element of the tourism phenomenon. Implicit values should also be instilled and the dynamism of curricular content should be considered in curriculum design. Therefore, the author proposes a conceptual framework for global development. The framework reflects the development of thought from three key regions, namely, the UK, Europe, and the US, where tourism knowledge and curriculum originated and developed. Tourism knowledge is argued to positively affect higher education, particularly in the undergraduate level, in countries where tourism degrees are offered.

After applying the proposed framework, the outcome will produce well-rounded tourism graduates who see themselves as assets to the industry. Additionally, these graduates are expected to have developed analytical and critical skills required to understand the significance of their acquired knowledge within the context of a greater path. The conceptual frameworks and its explanation are illustrated in Figure 3.

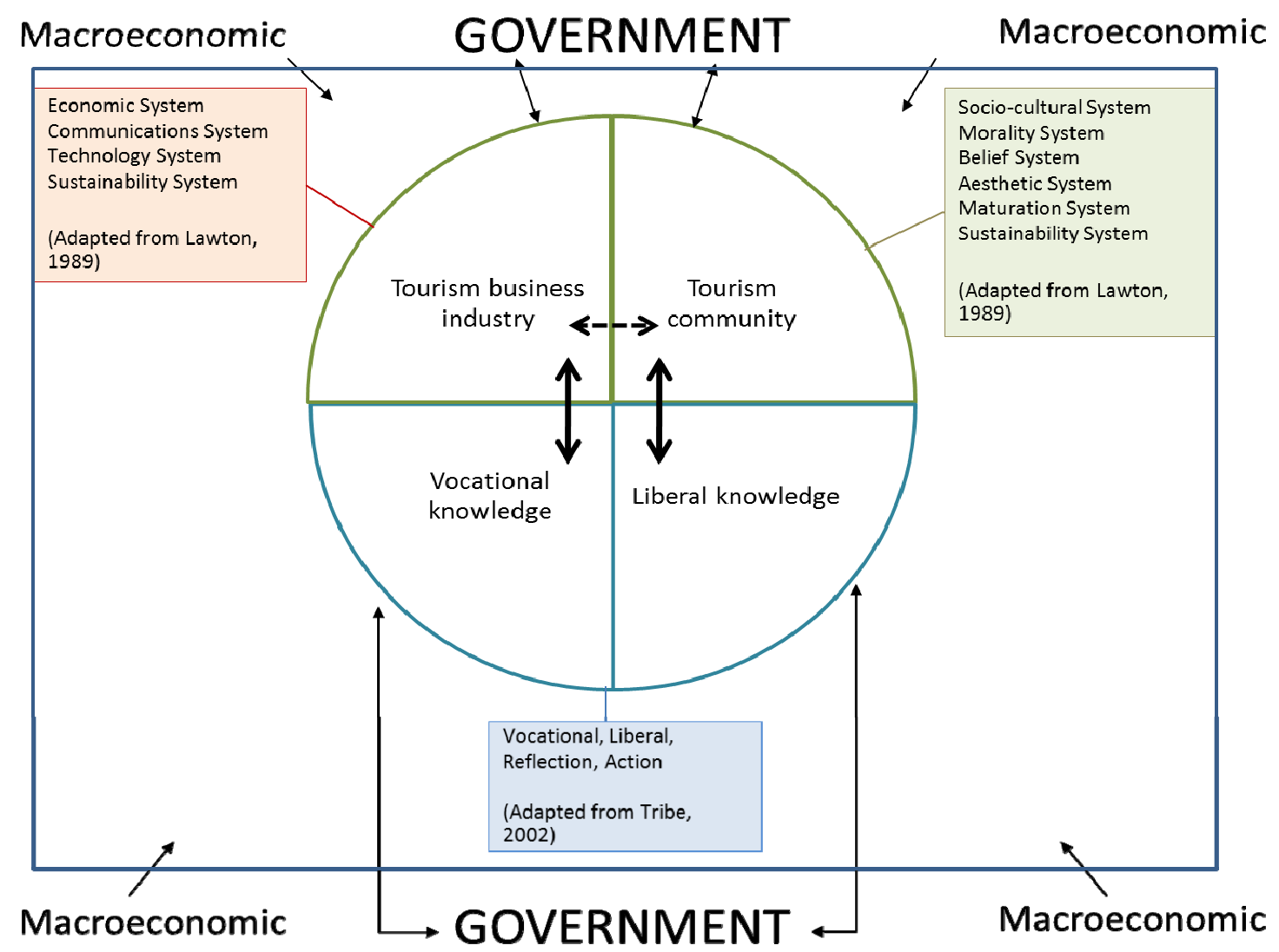

Figure 3. Proposed conceptual framework for tourism curriculum as part of a larger system

First, the proposed framework offers a range of knowledge with two main aspects, namely, tourism business industry and tourism community. Both aspects are part of the tourism phenomenon. Tourism educators must consider both sides when deciding subject components for curriculum insertion.

Second, both curriculum frameworks by Lawton (1989) and Tribe (2002) are included in the proposed framework through the addition of the new "sustainability system" element. These two frameworks by Lawton and Tribe represent important implicit values to the tourism curriculum. Incorporating these values will create tourism graduates who have humanity values, holistic understanding of his/her connection with the society and/or to the larger system, and good vocational skills required by the industry. The framework proposes the new "sustainability system" element in addition to the proposal of Lawton. Such a measure will reflect the current and critical trends in the global phenomenon of tourism. The "sustainability system" element is important in both 
tourism business industry and social community aspects. From the perspective of the educator, selected knowledge is divided into two streams. First, vocational/technical knowledge seeks to fulfill industry needs. Second, in accordance with Tribe's proposal, liberal knowledge fulfills social and philosophical aspects in the tourism community. Furthermore, the arrows in the middle of the framework represent the give-and-take relationship among the tourism curriculum, industry, and tourism community elements. This process is dynamic and requires the participation and communication of all parties. The dynamic process thus forces tourism educators to find the appropriate subjects and/or mechanisms to call the attention of the industry and tourism community. The relationship between tourism education and both the industry and the tourism community are explicit. Both arrows are represented in solid line to indicate the results of curriculum development. However, the existing relationship between the industry and the community resulting from curriculum is more implicit. Therefore, the relationship is represented by a dashed line.

Lastly, external to the rectangular area are other powerful factors, such as government and macro-economic tourism supply and demand. These factors can have a major influence on the tourism curriculum. Educators must be aware of these external factors. For example, Botterial and Gale (2005) state that the government supports the funding of education institutions those work closely with industry to ensure economic competitiveness. The academic community could then examine whether or not power is exerted within cautious conditions, and whether or not the imposed regulation is in favor of the business sector or the social community. Educators have the right to provoke and to set the balance between these forces within their designed curriculum. Furthermore, the designed curriculum should be created with the awareness of the overall available tourism resources and the corresponding supply and demand.

\section{Conclusion}

The study elaborates the development of the tourism curriculum over the past twenty years. The article determined the key points worth addressing in each period which took place in Europe, UK and US where tourism curriculum was strongly established. From its roots in pragmatic vocational education, the tourism curriculum developed into a curriculum for tourism in higher education. Nevertheless, the development process has passed through criticism and feedback regarding its purpose, meaning, and direction. This development path was observed through three main periods. First, prior to 1990, academics began to search for a clear definition of the "tourism curriculum," and to determine important deliverable components of tourism. In addition, academics pursued how to view the subject of tourism as a field or a discipline. Second, between the 1990s and 2000, academics discussed the extent of the support of tourism for business perspectives, and the inclusion of the philosophical core of social science in tourism. Third, the use of various methodologies was explored to examine the direction of tourism curriculum. The introduction of the curriculum design mechanism, such as the concept of the curriculum space, was elaborated.

We highlight the concern that the existing tourism curriculum produces graduates with limited perspectives of the tourism industry. We elaborate on the reasons for the existence of tourism and its connection with society. The tourism curriculum is a part of a larger system and addresses the need to create well-rounded tourism graduates. These graduates should position themselves as model employees and citizens and should advance their understanding of the interrelationship between the tourism phenomenon and acquired tourism knowledge. The proposed framework serves this purpose and can thus be used in a global context. The proposed conceptual framework should further be investigated to test its reliability and validity and to evaluate whether it can yield desirable outcomes and be applied to all stakeholders.

\section{References}

Airey, D. (1979). Tourism education in the United Kingdom. Tourist Review, 34(2), 13-15.

Airey, D. (2004). From here to uncertainty. Critical Issues in Tourism Education (pp. 9-15). Buckinghamshire, UK: ATHE Publication.

Airey, D., \& Johnson, S. (1999). The content of tourism degree courses in the UK. Tourism Management, 20, 229-235. http://dx.doi.org/10.1016/S0261-5177(98)00079-X

Airey, D., \& Middleton, V. (1984). Course syllabi in the UK: A review. Tourism Management, 57-62. http://dx.doi.org/10.1016/0261-5177(84)90008-6

Ayikoru, M. (2004). A discursive semiotic analysis of tourism higher education texts. Critical Issues in Tourism Education (pp. 9-15). Buckinghamshire, UK: ATHE Publication.

Ayikoru, M., Tribe, J., \& Airey, D. (2009). Reading tourism education neoliberalism unveiled. Annals of Tourism Research, 36(2), 191-221. http://dx.doi.org/10.1016/j.annals.2008.11.001 
Belhassen, Y., \& Caton, K. (2011). On the need for critical pedagogy in tourism education. Tourism Management, 32, 1389-1396. http://dx.doi.org/10.1016/j.tourman.2011.01.014

Botterill, D., \& Gale, T. (2005). Postgraduate and PhD education. In D. Airey, \& J. Tribe (Eds.), An International Handbook of Tourism Education (pp. 469-480). Oxford: Elsevier. http://dx.doi.org/10.1016/B978-0-08-044667-7.50036-7

Busby, G. (2001). The Culture of Education. Cambridge, MA: Harvard University Press.

Bodewes, T. G. (1981). Development of advanced tourism studies in Holland. Annals of Tourism Research, 35-51. http://dx.doi.org/10.1016/0160-7383(81)90066-9

Chaisawat, M. (2006). Travel and tourism education in Thailand. Journal of teaching in travel \& tourism, 5(3), 197-224. http://dx.doi.org/10.1300/J172v05n03_02

Council for National Academic Awards. (1993). Review of tourism studies degree courses. London: CNAA.

Dale, C., \& Robinson, N. (2001). The theming of tourism education: A three-domain approach. International Journal of Contemporary Hospitality Management, 13(1), 30-34. http://dx.doi.org/10.1108/09596110110365616

Goodlad, S. (1995). The quest for quality. Buckingham: Open University Press.

Gunn, C. A. (1998). Issues in tourism curriculum. Journal of Travel Research, 36, 74-77. http://dx.doi.org/10.1177/004728759803600410

Halloway, J. C. (1995). Towards a core curriculum for tourism: A discussion paper. London: The National Liaison Group for Higher Education in Tourism.

Inui, Y., Wheeler, D., \& Lankford, S. (2006). Rethinking tourism education: What should schools teach? Journal of Hospitality Leisure, Sport, and Tourism Education, 5(2), 26-36. http://dx.doi.org/10.3794/johlste.52.122

Jafari, J. (1977). Editor's page. Annals of Tourism Research, 5, 6-11. http://dx.doi.org/10.1016/S0160-7383(77)80002-9

Jafari, J., \& Ritchie, J. B. (1981). Toward a framework for tourism education: Problems and prospects. Annals of tourism research, 13-34. http://dx.doi.org/10.1016/0160-7383(81)90065-7

Koh, K. (1995). Designing the four-year tourism management curriculum: A marketing approach. Journal of Travel Research, 34, 68-72. http://dx.doi.org/10.1177/004728759503400109

Kuhn, T. S. (1970). The structure of scientific revolutions. Chicago: University of Chicago Press.

Lashly, C. (2004). Escaping the tyranny of relevance: Some reflections on hospitality management education. Critical Issues in Tourism Education (pp. 9-15). Buckinghamshire, UK: ATHE Publication.

Lawton, D. (1989). Education, culture and the national curriculum. London: Hodder and Stoughton.

Lawton, D. (1996). Beyond the national curriculum. London: Hodder and Stoughton.

Lewis, A. (2004). Rationalising a tourism curriculum for sustainable tourism development in small island states: A stakeholder perspective. Critical Issues in Tourism Education (pp. 9-15). Buckinghamshire, UK: ATHE Publication.

Lo, A. (2005). The past, present, and future of hospitality and tourism higher education in Hong Kong. In C. Hsu (Ed.), Global Tourism Higher Education: Past, Present, and Future (pp. 137-166). New York: The Haworth Hospitality Press.

McKercher, B. (2002). The future of tourism education: An Australian scenario? Tourism and Hospitality Research, 3(3), 199-210.

Morgan, M. (2004). From production line to drama school: Higher education for the futue of tourism. International Journal of Contemporary Hospitality Management, 16(2), 91-99. http://dx.doi.org/10.1108/09596110410519973

Middleton, V. T. C., \& Ladkin, A. (1996). The profile of tourism studies degree courses in the UK: 1995/6. London: National Liaison Group.

Morrison, A., \& O'Mahony, G. B. (2003). The liberation of hospitality management education. International Journal of Eontemporary Hospitality Management, $\quad 15(1), \quad 38-44$. http://dx.doi.org/10.1108/09596110310458972 
Ring, A., Dickinger, A., \& Wober, K. (2009). Designing the ideal undergraduate program in tourism: Expectations from industry and educators. Journal of Travel Research, 48(1), 106-121. http://dx.doi.org/10.1177/0047287508328789

Rowntree, D. (1982). Educational technology in curriculum development. London: Harer \& Row/Paul Chapman.

Scrimshaw, P. (1983). Educational ideologies (Unit2, E204) purpose and planning in the curriculum. Milton Keynes: Open University Press.

Silver, H., \& Brennan, L. (1988). A liberal vocationalism. London: Hoder and stoughton. http://dx.doi.org/10.4324/9780203472514

Smith, G., \& Cooper, C. (2000). Competitive Approaches to Tourism and Hospitality Curriculum Design. Journal of Travel Research, 39, 90-95. http://dx.doi.org/10.1177/004728750003900112

Squires, G. (1990). First degree: The undergraduate curriculum. Buckingham: Open University Press.

Taylor, P., \& Richard, C. (1985). An introduction to curriculum studies. Windsor: NFER-Nelson.

Tribe, J. (1997). The indiscipline of tourism. Annals of Tourism Research, 24(3), 638-67. http://dx.doi.org/10.1016/S0160-7383(97)00020-0

Tribe, J. (2001). Research paradigms and the tourism curriculum. Journal of travel research, 39, 442-448. http://dx.doi.org/10.1177/004728750103900411

Tribe, J. (2002). The philosophic practitioner: A curriculum for tourism stewardship. Annals of Tourism Research, 29(2), 338-357. http://dx.doi.org/10.1016/S0160-7383(01)00038-X

Tribe, J. (2005). Tourism, knowledge, and the curriculum. In D. Airey, \& J. Tribe (Eds.), International Handbook of Tourism Education (pp. 47-60). Amsterdam: Routledge. http://dx.doi.org/10.1016/B978-0-08-044667-7.50007-0

Zhang, W., \& Fan, X. (2006). Tourism higher education in China: Past and present, opportunities and challenges. Journal of teaching in travel \& tourism, 5(1-2), 117-135. http://dx.doi.org/10.1300/J172v05n01_06

\section{Copyrights}

Copyright for this article is retained by the author(s), with first publication rights granted to the journal.

This is an open-access article distributed under the terms and conditions of the Creative Commons Attribution license (http://creativecommons.org/licenses/by/3.0/). 